\title{
Awareness of HPV-associated oropharyngeal cancers among GPs in The Netherlands: a cross-sectional study
}

\section{Imke Demers ${ }^{1}$, Femke Verhees ${ }^{2}$, Leo J Schouten ${ }^{3}$, Jean WM Muris ${ }^{4}$, Bernd Kremer ${ }^{2}$, Ernst Jan M Speel ${ }^{1 *}$}

1Department of Pathology, GROW-school for Oncology and Developmental Biology, Maastricht University Medical Center, Maastricht, The Netherlands; ${ }^{2}$ Department of Otorhinolaryngology, Head and Neck Surgery, GROW-school for Oncology and Developmental Biology, Maastricht University Medical Center, Maastricht, The Netherlands; ${ }^{3}$ Department of Epidemiology, GROW-school for Oncology and Developmental Biology, Maastricht University Medical Center, Maastricht, The Netherlands; ${ }^{4}$ Department of Family Medicine, CAPHRI Care and Public Health Research Institute, Maastricht University Medical Center, Maastricht, The Netherlands
*For correspondence: ernstjan. speel@mumc.nl

Competing interest: See page 9

Received: 09 May 2021

Accepted: 12 July 2021

Published: 15 December 2021

@This article is Open Access: CC BY license (https://creativecommons.org/licenses/by/4.0/)

Author Keywords: crosssectional studies, general practitioners, human papillomavirus 16, oropharyngeal neoplasms, primary health care, risk factors

Copyright (C) 2021, The Authors; DOI:10.3399/BJGPO.2021.0080

\begin{abstract}
Background: The incidence of human papillomavirus (HPV)-associated oropharyngeal cancer (OPC) is increasing in high income countries. HPV-associated OPC generally presents as an invasive disease, often with lymph node involvement, in relatively young patients with minimal or no history of smoking and alcohol consumption. Knowledge on HPV-associated OPC among primary care professionals is essential for disease recognition and early start of treatment.
\end{abstract}

Aim: To examine the knowledge on HPV-associated OPC among GPs in the Netherlands.

Design \& setting: A cross-sectional postal survey among GPs in the Netherlands.

Method: A 12-item questionnaire was sent to 900 randomly selected general practices. Outcome measures included awareness of the link between HPV and OPC, epidemiological trends, and patient characteristics. Data were statistically analysed for sex, years after graduation, and self-rated knowledge of OPC.

Results: A total of 207 GPs participated in this study. Seventy-two per cent recognised HPV as a risk factor for OPC and $76.3 \%$ were aware of the increasing incidence rate of HPV-associated OPC. In contrast, $35.7 \%$ of participants knew that patients with HPV-associated OPC are more often male, and just over half (53.6\%) of the participants were aware of the younger age of these patients.

Conclusion: More than one-quarter of GPs in the Netherlands are unaware of HPV as a causative factor for OPC. Furthermore, there is a gap in knowledge on characteristics of patients with HPV-associated OPC. Further training on these topics could improve disease recognition and, ultimately, patient survival.

\section{How this fits in}

Since HPV-associated OPC generally presents in a group of relatively young patients without typical risk factors, disease recognition can pose challenges for GPs without detailed knowledge of the disease and corresponding patient characteristics. A meta-analysis on the knowledge on HPVassociated OPC among different populations revealed that the knowledge on HPV in OPC among medical and dental professionals varied from 26-91\%. In the current study, the awareness of the link 
between HPV and OPC, including epidemiological trends and demographic patient profiles, among GPs in the Netherlands was investigated for the first time. The results of this study identify areas where further education for GPs is needed to increase specific knowledge to improve disease recognition and patient outcomes.

\section{Introduction}

Head and neck cancer (HNC) was the seventh most common cancer worldwide in 2018, accounting for $3 \%$ of all cancers. ${ }^{1}$ Five-year, age-standardised relative survival rates range from $25-60 \%$, depending on anatomical location, HPV status, and stage at diagnosis. ${ }^{2} \mathrm{HNC}$ is usually diagnosed in older patients in association with tobacco use and heavy alcohol consumption. ${ }^{3-5}$ In addition, infection with high-risk HPV, primarily HPV type 16, has been recognised as a major risk factor for the development of HNC, specifically OPC. Partly as a result of the worldwide decline in tobacco use, the incidence of HNC has decreased over recent decades. Conversely, the incidence of HPV-associated OPC is increasing in so-called 'high income' countries, including Australia, the US, Canada, Sweden, Denmark, and the Netherlands. ${ }^{3,6-9}$ A meta-analysis including 5396 OPCs observed an increase in the proportion of HPVrelated OPC from 40.5\% before 2000 to 72.2\% after 2005, with significant increases in North America and Europe. ${ }^{10}$ In the Netherlands, an increase in the prevalence of HPV in OPC was observed from $5.1 \%$ in 1990 to $29 \%$ in $2010 .{ }^{9}$ More recent studies showed a prevalence of HPV in $30-50 \%$ of the OPC cases in the Netherlands. ${ }^{11-13}$

HPV-associated OPC is considered to be a distinct clinical and molecular entity. ${ }^{14,15}$ In contrast to patients with non-HPV-associated OPC, patients with HPV-associated OPC are younger, more often male, have a higher socioeconomic status and more lifelong sexual partners, and are less likely to have a history of extensive tobacco and alcohol use. ${ }^{3,15,16}$ Compared with non-HPVassociated tumours, HPV-associated tumours are generally characterised by a better prognosis, primarily because they are more responsive to chemotherapy and radiotherapy. ${ }^{17,18}$ Despite this beneficial treatment response, HPV-associated tumours often have a peculiar clinical presentation. Compared with non-HPV-associated tumours, HPV-associated tumours generally present as smaller (asymptomatic) tumours, but often with regional lymph node metastases and sometimes even with presentation of neck metastases from an occult primary tumour. ${ }^{19-21}$ Diagnosis of oropharyngeal HPV-associated tumours at earlier disease stage is associated with improved overall and diseasespecific survival rates. ${ }^{22}$ Furthermore, HPV-associated OPC precursor lesions are scarce, unlike cervical cancer, which means that no validated preventive screening method has been developed for these tumours. ${ }^{23-25}$ Therefore, early disease recognition by primary care professionals and no delay in treatment are crucial for patient outcomes.

Recognising patients at risk of HPV-associated OPC can pose challenges for GPs, who may not have detailed knowledge of the disease and corresponding patient characteristics. A systematic review by Dodd et al identified 41 studies investigating the knowledge about the link between HPV and OPC in different populations. ${ }^{26}$ This study revealed that the lowest knowledge was observed in the general population (1-44\%), which can be confirmed in a recent study in the Netherlands showing that only $11 \%$ of the general population was aware of the link between HPV and OPC $(29.2 \%$ of people stated they were aware of the existence of HPV). ${ }^{27}$ The same systematic review reported that the highest knowledge on HPV in OPC was reported among medical and dental professionals (26-91\%), which was also found by a recent study by Lechner et al in the UK, reporting that $74 \%$ of GPs recognised HPV as a risk factor for OPC. ${ }^{28}$

This study is the first to assess awareness of the link between HPV and OPC, the epidemiological trends in (HPV-associated) OPC and demographic profiles of patients with HPV-associated OPC among a randomly selected group of GPs in the Netherlands. The results might identify areas where further education for GPs are needed to increase specific knowledge, and thereby improve disease recognition and patient outcomes. 


\section{Method}

\section{Survey design}

A cross-sectional questionnaire survey was performed among GPs in the Netherlands. A short questionnaire was adapted and translated from an already developed questionnaire by Lechner et $\mathrm{l}^{28}$ (Supplementary File S1). This questionnaire assessed demographic characteristics of participants, self-rated knowledge of OPC, awareness of OPC risk factors, knowledge on the association between HPV and OPC, and characteristics of patients with HPV-associated OPC. Demographic characteristics included sex, years since graduation, and current position. Selfrated knowledge on OPC was assessed by a Likert scale. To assess the awareness of risk factors, 11 risk factors (of which eight were correct and three were false) were selected from epidemiological literature.

\section{Participants}

The postal addresses of 900 GPs throughout the Netherlands were obtained from the Netherlands Institute for Health Services Research (NIVEL). These 900 GPs were selected by random sampling of all GPs registered at NIVEL, comprising approximately $85-90 \%$ of all GPs in the Netherlands. A response rate of $20 \%$ was anticipated based on previous surveys among GPs (NIVEL, institutional communication). The questionnaire was administered in September 2020 to the GPs by mail. To increase the response rate, questionnaires could be completed both in paper format and by a link to the online platform

Survey Monkey. In addition, a reminder was sent 2 weeks after the initial invitation. Answers of returned paper questionnaires were added as separate collectors to the Survey Monkey database. Both paper format and online questionnaires were collected anonymously. After completing the questionnaire, participants were given a factsheet with information about HPV and HPV-associated OPC (Supplementary file 2).

\section{Statistical analysis}

Statistical analyses were performed using SPSS statistical software for Windows (version 20), and Stata (version 14.1). Descriptive analyses with calculated measures of central tendency and variation were computed, along with frequency tables for categorical variables. Whether distributions of categories are different was tested using $\chi^{2}$ tests and likelihood ratio tests. The extended Mantel-Haenszel stratified test of association was used to test for linear trends. For this, variables were recoded into two categories (the 'correct' answers and 'incorrect answers'). $P$ values below 0.05 were considered statistically significant. 


\section{Results}

\section{Participants' characteristics}

The questionnaire was sent to $900 \mathrm{GPs}$ throughout the Netherlands. Overall, 212 questionnaires were collected, resulting in a response rate of $23.6 \%$. The majority of the questionnaires were completed in paper format compared with the online questionnaire (141 versus 71$)$. Five questionnaires were incomplete (6-9 missing answers of 12 questions in total) and therefore excluded from analysis. The demographic characteristics of participants are shown in Table 1. Owing to the applied privacy legislation, it was not possible to compare features between responders and non-responders. Nevertheless, responders could be compared with the whole registry of GPs in the Netherlands (in 2019) for sex, current position, and GP experience. ${ }^{29,30}$ Supplementary Table S1 shows that only the percentage of female GPs is different in the whole registry (58\%) versus the present study population (48\%). Notably, 49 out of 207 responding GPs (23.7\%) rated their knowledge of OPC as 'poor'.

\section{Knowledge of HPV and risk factors for OPC}

Of all 207 responders, 72.0\% were aware of the link between HPV infection and OPC; $23.7 \%$ were not aware of this link and $4.3 \%$ were not sure (Table 2). To assess awareness of risk factors for OPC in general, responders were confronted with 11 risk factors and asked whether these present risk factors for OPC or not (Table 3). Infection with HPV was recognised as a risk factor for OPC by $78.7 \%$ of participants. Participants had good knowledge of the risk factors smoking, alcohol abuse, and chewing of tobacco $(100 \%, 98.1 \%$, and $91.3 \%$, respectively). Chewing of betel leaf, betel palm, or betel nut (Areca nut); poor oral hygiene; family history; and low fruit and vegetable consumption were less well recognised as risk factors $(28.0 \%, 51.7 \%, 56.5 \%$, and $31.4 \%$, respectively).

Over three-quarters of participants were aware of the increase of HPV-associated OPC cases over the past two decades (76.3\%). A linear trend with years after graduation was not observed $(P=0.265)$. In contrast, only $19.8 \%$ were aware of the decrease in smoking-associated OPC rates during the same period. Interestingly, male GPs were significantly more aware of this decrease compared with female $\operatorname{GPs}(P=0.021)$ (Table 2).

\section{Knowledge of HPV-associated OPC patient characteristics}

Knowledge of HPV-associated OPC patient characteristics among GPs is essential for disease recognition and early start of treatment. Only $35.7 \%$ of all participants knew that OPC patients with HPV-associated tumours are more often male, and a comparable percentage $(34.3 \%)$ did not know (Table 4). GPs who rated their knowledge of OPC as 'good' were more aware of this sex difference ( $P$ $=0.003)$. However, this is a small group of only $10 \mathrm{GPs}(4.8 \%$ of total, Table 1$)$ and a linear trend for self-rated knowledge of OPC and awareness of the male sex of patients was not observed $(P=0.152)$.

That HPV-associated OPC patients are generally aged $<60$ years was correctly recognised by just over half of participants (53.6\%). Interestingly, GPs with a self-rated knowledge of 'good' were less aware of the younger age of these patients, but no statistically significant trend was observed $(P=$ 0.981). Notably, only $17.4 \%$ were aware that HPV-associated OPC patients generally have a better prognosis compared with non-HPV-associated OPC patients. Despite the small group size, GPs still in training and/or graduated $<2$ years ago were more aware of this better prognosis ( $37.5 \%$ ) compared with their colleagues who graduated $>2$ years ago: $16.7 \%$ for $2-5$ years, $15.4 \%$ for $5-10$ years, $23.7 \%$ for $10-20$ years, and $9.3 \%$ for $>20$ years after graduation. A trend towards significance was observed $(P=0.054)$. More than half of all GPs did not know about the generally better prognosis of these patients (57.0\%) (Table 4).

\section{Discussion}

\section{Summary}

The incidence of HPV-associated OPC is increasing in high income countries, including the Netherlands. ${ }^{3,6,8,10}$ Although these tumours often present with invasive properties and regional lymph node metastases, their prognosis is usually favourable compared with non-HPV-associated tumours. ${ }^{21}$ Early disease recognition by primary care professionals and no delay in the start of treatment are crucial for patient outcomes. The aim of this study was to assess, for the first time, the awareness of 


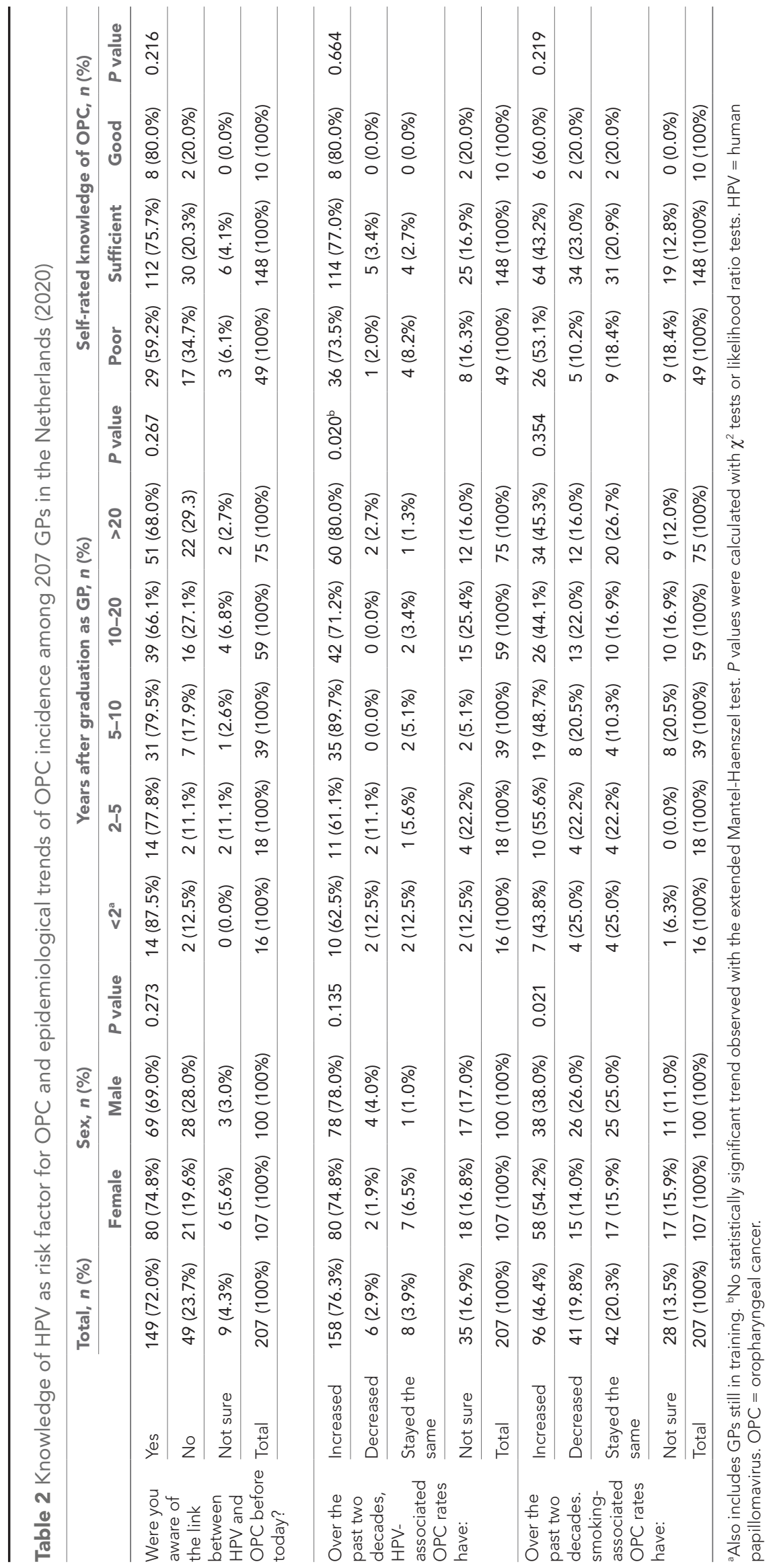


Table 3 Knowledge of reported risk factors for oropharyngeal cancer among 207 GPs in the Netherlands (2020)

\begin{tabular}{lcccccc}
\hline & Yes & \multicolumn{2}{c}{ No } & \multicolumn{2}{c}{ Not sure } \\
\cline { 2 - 7 } Risk factor & $\boldsymbol{n}$ & $\%$ & $\boldsymbol{n}$ & $\%$ & $\mathbf{n}$ & $\%$ \\
\hline Smoking & 207 & 100.0 & 0 & 0.0 & 0 & 0.0 \\
\hline Alcohol abuse & 203 & 98.1 & 1 & 0.5 & 3 & 1.4 \\
\hline Chewing of tobacco & 189 & 91.3 & 4 & 1.9 & 14 & 6.8 \\
\hline Chewing of betel leaf/palm/nut & 58 & 28.0 & 12 & 5.8 & 137 & 66.2 \\
\hline Marijuana use & 106 & 51.2 & 24 & 11.6 & 77 & 37.2 \\
\hline Poor oral hygiene & 107 & 51.7 & 54 & 26.1 & 46 & 22.2 \\
\hline Herpes simplex virus infection & 27 & 13.0 & 99 & 47.8 & 81 & 39.1 \\
\hline Human papillomavirus infection & 163 & 78.7 & 9 & 4.3 & 35 & 16.9 \\
\hline Positive family history & 117 & 56.5 & 40 & 19.3 & 50 & 24.2 \\
\hline Low fruit and vegetable consumption & 65 & 31.4 & 47 & 22.7 & 95 & 45.9 \\
\hline Sun exposure & 34 & 16.4 & 110 & 53.1 & 63 & 30.4 \\
\hline
\end{tabular}

Herpes Simplex virus infection, marijuana use, and sun exposure are not proven risk factors for oropharyngeal cancer.

the link between HPV and OPC and knowledge of associated patient characteristics in a sample of GPs in the Netherlands. The results show that of the responding GPs: 1) $72.0 \%$ were aware of the link between HPV and OPC; 2) $76.3 \%$ were aware that HPV-associated OPC rates have increased over the past two decades; and 3 ) only $35.7 \%$ were aware of sex, $53.6 \%$ were aware of age, and $17.4 \%$ were aware of prognosis of patients with HPV-associated OPC.

\section{Strengths and limitations}

Participants were selected by random sampling of all GPs registered at NIVEL, comprising $85-90 \%$ of all GPs in the Netherlands, minimising sampling bias. Furthermore, to minimise response bias, GPs were offered the choice to complete the questionnaire via an online link or on paper. Since the response rate was relatively low, and there is no information on non-responders owing to applied privacy legislation, any (non)response bias that may affect the interpretation of the results of the study cannot be tested. However, it was observed that the percentage of female GPs in the study sample was lower compared with the whole registry of GPs (Supplementary Table S1). Furthermore, participants may have looked at subsequent questions when filling in the paper-format questionnaire, which may have influenced their answers. In the online questionnaire, questions could only be answered in sequence. When comparing the online-format questionnaires with the paper-format questionnaires, however, no difference was observed in awareness of HPV in OPC $(73.9 \%$ for online versus $71.0 \%$ for paper).

\section{Comparison with existing literature}

Previous studies investigating the knowledge on the role of HPV in HNC among medical and dental professionals show varying awareness rates from $26-91 \%{ }^{26}$ The awareness rate of GPs in this study $(72 \%)$ is comparable to the awareness reported for GPs in the UK (74\%) and Poland (80\%). ${ }^{28,31}$ The latter study used different outcome variables to assess knowledge of HPV-associated OPC, by asking, 'How important is the impact of HPV on the development of upper respiratory tract pathology?', rather than, 'Have you heard about the link between HPV and OPC before today?' (Table 5). This may induce bias in the interpretation of the actual awareness percentage and could make direct comparison difficult. In contrast, the awareness among GPs in the present study is higher than in Jordan (43.3\%), Germany (54\%), and Italy (38\%) ${ }^{32-34}$ (Table 5). However, these studies were performed $>5$ years ago and increasing knowledge on HPV and OPC over the years and the introduction of the $\mathrm{HPV}$ vaccine might have influenced awareness rates among GPs. 


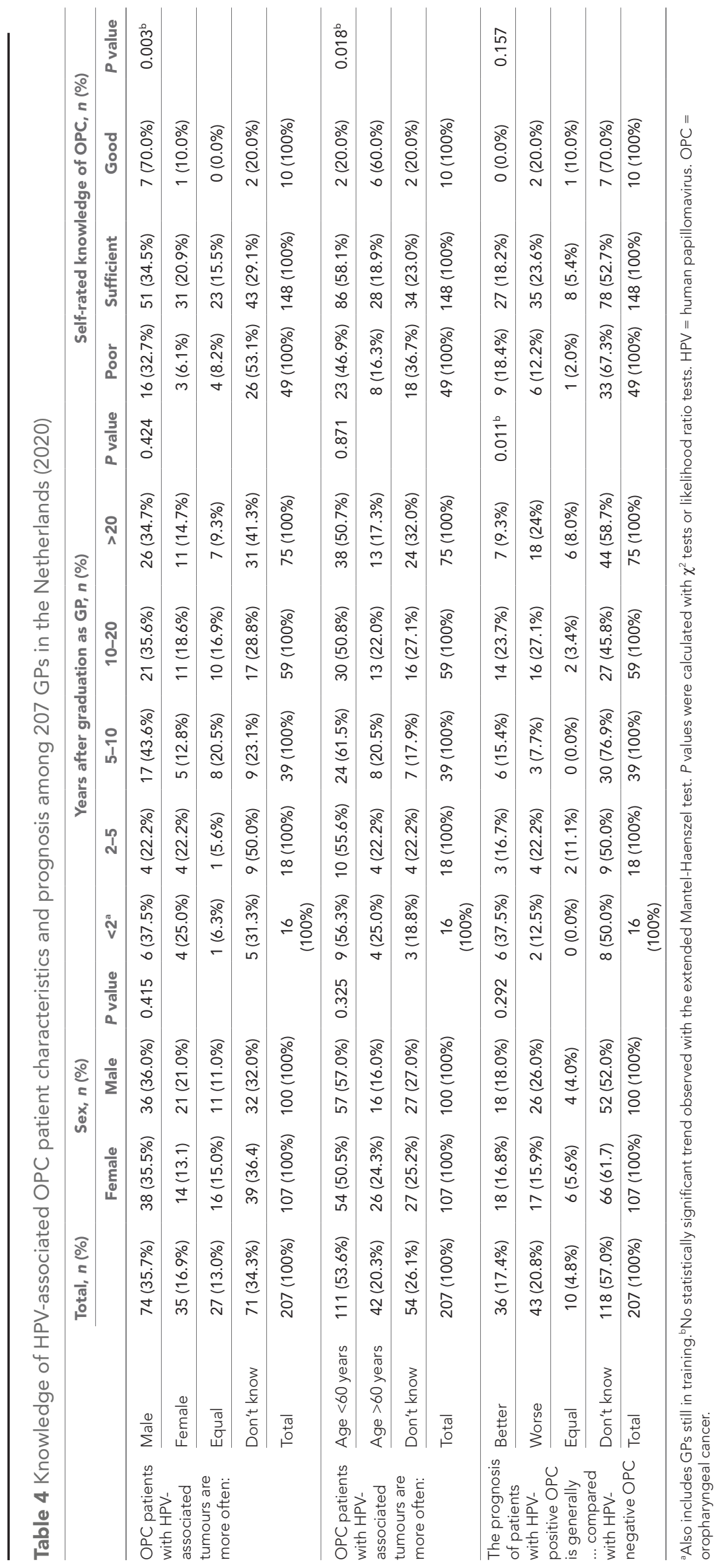


Table 5 Overview and results of published studies reporting on awareness of HPV in the development of head and neck cancers among GPs and other healthcare professionals (2014-2018)

\begin{tabular}{|c|c|c|c|c|}
\hline Author & Year & Country & $\begin{array}{l}\text { Study } \\
\text { population }\end{array}$ & Results \\
\hline Hertrampf $f^{33}$ & 2014 & $\begin{array}{l}\text { Germany } \\
\text { (Schleswig- } \\
\text { Holstein) }\end{array}$ & $\begin{array}{l}33 \text { ENTs, } \\
192 \text { GPs, } \\
135 \text { IMs, } \\
28 \text { DERMs }\end{array}$ & $\begin{array}{l}\text { HPV recognised as a risk factor for oral cancer by } 70 \% \text { of ENTs, } 54 \% \text { of GPs, } 51 \% \text { of IM, } \\
\text { and } 82 \% \text { of DERMs }\end{array}$ \\
\hline Signorelli ${ }^{34}$ & 2014 & Italy & $938 \mathrm{GPs}$ & $38 \%$ were aware of HPV as a risk factor for oral cancer. \\
\hline Jackowska ${ }^{31}$ & 2015 & Poland & $\begin{array}{l}144 \text { ENTs, } \\
192 \text { GPs, } \\
68 \text { trainees }\end{array}$ & $\begin{array}{l}\text { Of the GPs, the importance of HPV in the development of OPC was rated as 'Large' } \\
\text { by } 28.6 \% \text {, as 'I know the problem' by } 44.8 \% \text {, as 'Overrated' by } 6.8 \% \text {, and as 'Have not } \\
\text { heard about the problem' by } 19.2 \% \text {. }\end{array}$ \\
\hline Hassona ${ }^{32}$ & 2016 & Jordan & $\begin{array}{l}165 \text { dentists, } \\
165 \text { GPs }\end{array}$ & $\begin{array}{l}43.3 \% \text { were aware of HPV as a risk factor for oral cancer. } \\
\text { No significant difference was found between dentists and GPs }\end{array}$ \\
\hline Lechner $^{28}$ & 2018 & UK & 384 GPs & 73.9\% were aware of HPV as a risk factor for OPC \\
\hline
\end{tabular}

ENT = ear nose and throat. IM = internal medicine. DERM = dermatologist. HPV = human papillomavirus. OPC = oropharyngeal cancer.

The present study showed that the knowledge on HPV-associated OPC patient characteristics and prognosis is limited. The UK study also noticed this knowledge gap, describing that $41.5 \%$ of GPs identified HPV-associated OPC as being more common in men, and $58.8 \%$ correctly reported the association with younger age. ${ }^{28}$ Interestingly, the results show that GPs in training or recently graduated GPs had greater knowledge of the favourable prognosis. These data suggest that education is necessary to further increase awareness of patient prognosis and demographics of HPV-associated OPC.

Several similar studies among the general population suggest that the awareness of the role of HPV in the development of cervical cancer is relatively high. However, people were shown to be less informed about the role of HPV in OPC. ${ }^{35-37}$ A recent study in the Netherlands showed that $30.6 \%$ of 1044 participants had heard of HPV and only $29.2 \%$ of these (11.0\% of all participants) knew about the association between HPV and OPC. ${ }^{27}$ Importantly, knowledgeable GPs could play an important role in prevention of HPV-associated disease by educating the general public and encouraging the uptake of the HPV vaccine.

\section{Implications for practice}

The results show that the sample of GPs in this study is reasonably aware of HPV as a causative factor for OPC. Nevertheless, more than one-quarter of GPs are still unaware of this link. Specifically, knowledge on less common risk factors and characteristics of patients at risk of HPV-associated OPC should be improved. This knowledge is important as HPV-associated tumours generally present in a relatively young patient population, without typical risk factors, and OPC might therefore be less well recognised in these patients. In terms of educational resources, the authors created a factsheet containing information about HPV and OPC, which was sent to all GPs participating in this study. In addition, further training in the form of regional and national meetings may contribute to better targeted knowledge of these topics, leading to HPV-associated disease prevention, improved disease recognition in the primary care setting, and, ultimately, appropriate referral of patients to secondary care.

Funding

This research received no external funding.

Ethical approval

The medical ethical committee of Maastricht University Medical Center gave approval for survey data collection (METC 2020-1887).

Provenance

Freely submitted; externally peer reviewed. 


\section{Acknowledgements}

The authors would like to thank Matt Lechner, Head and Neck Centre, University College London Hospitals NHS Trust, for his critical review of the manuscript. Furthermore, they would like to thank NIVEL for providing them with address information of 900 general practices in the Netherlands, and all GPs who participated in this study.

\section{Competing interests}

Imke Demers, Femke Verhees, Jean WM Muris, and Leo J Schouten declare no conflict of interest. Bernd Kremer reports grants from Pfizer and Novartis, outside the subject of this study. Ernst Jan Speel reports grants from Pfizer and Novartis and honoraria from BMS, outside the subject of this study.

\section{References}

1. Bray F, Ferlay J, Soerjomataram I, et al. Global cancer statistics 2018: GLOBOCAN estimates of incidence and mortality worldwide for 36 cancers in 185 countries. CA Cancer J Clin 2018; 68(6): 394-424. DOI: https://doi.org/ 10.3322/caac.21492

2. Gatta G, Botta L, Sánchez MJ, et al. Prognoses and improvement for head and neck cancers diagnosed in Europe in early 2000s: the EUROCARE-5 population-based study. Eur J Cancer 2015; 51(15): 2130-2143. DOI: https://doi. org/10.1016/j.ejca.2015.07.043

3. Mourad M, Jetmore T, Jategaonkar AA, et al. Epidemiological trends of head and neck cancer in the United States: a SEER population study. J Oral Maxillofac Surg 2017; 75(12): 2562-2572. DOI: https://doi.org/10.1016/j.joms. 2017.05.008

4. Chow LQM. Head and neck cancer. N Engl J Med 2020; 382(1): 60-72. DOI: https://doi.org/10.1056/ NEJMra1715715

5. Maasland DHE, van den Brandt PA, Kremer B, et al. Alcohol consumption, cigarette smoking and the risk of subtypes of head-neck cancer: results from the Netherlands cohort study. BMC Cancer 2014; 14: 187. DOI: https:// doi.org/10.1186/1471-2407-14-187

6. Global Burden of Disease Cancer Collaboration, Fitzmaurice C, Allen C, et al. Global, regional, and national cancer incidence, mortality, years of life lost, years lived with disability, and disability-adjusted life-years for 32 cancer groups, 1990 to 2015: a systematic analysis for the Global Burden of Disease study. JAMA Oncol 2017; 3(4): 524-548. DOI: https://doi.org/10.1001/jamaoncol.2016.5688

7. Gooi Z, Chan JYK, Fakhry C. The epidemiology of the human papillomavirus related to oropharyngeal head and neck cancer. Laryngoscope 2016; 126(4): 894-900. DOI: https://doi.org/10.1002/lary.25767

8. Chaturvedi AK, Anderson WF, Lortet-Tieulent $\mathrm{J}$, et al. Worldwide trends in incidence rates for oral cavity and oropharyngeal cancers. J Clin Oncol 2013; 31(36): 4550-4559. DOI: https://doi.org/10.1200/JCO.2013.50.3870

9. Rietbergen MM, Leemans CR, Bloemena $E$, et al. Increasing prevalence rates of HPV attributable oropharyngeal squamous cell carcinomas in the Netherlands as assessed by a validated test algorithm. Int J Cancer 2013; 132(7): 1565-1571. DOI: https://doi.org/10.1002/ijc.27821

10. Mehanna H, Beech T, Nicholson T, et al. Prevalence of human papillomavirus in oropharyngeal and nonoropharyngeal head and neck cancer-systematic review and meta-analysis of trends by time and region. Head Neck 2013; 35(5): 747-755. DOI: https://doi.org/10.1002/hed.22015

11. Nauta IH, Rietbergen MM, van Bokhoven AAJD, et al. Evaluation of the eighth TNM classification on p16-positive oropharyngeal squamous cell carcinomas in the Netherlands and the importance of additional HPV DNA testing. Ann Oncol 2018; 29(5): 1273-1279. DOI: https://doi.org/10.1093/annonc/mdy060

12. Melchers LJ, Mastik MF, Samaniego Cameron B, et al. Detection of HPV-associated oropharyngeal tumours in a 16-year cohort: more than meets the eye. Br J Cancer 2015; 112(8): 1349-1357. DOI: https://doi.org/10.1038/bjc. 2015.99

13. Straetmans JM. HPV-related head and neck cancer: clinical features and implications for tumor staging and therapeutic strategies. Chapter 7: Additional parameters to improve the prognostic value of the 8th edition of the UICC classification for HPV-related oropharyngeal tumors [PhD dissertation]. Maastricht University. 2020; https:// www.kno-leden.nl/leden/document/view/id/6778 (accessed 15 Oct 2021).

14. Stransky N, Egloff AM, Tward AD, et al. The mutational landscape of head and neck squamous cell carcinoma. Science 2011; 333(6046): 1157-1160. DOI: https://doi.org/10.1126/science.1208130

15. Hafkamp HC, Manni JJ, Speel EJM. Role of human papillomavirus in the development of head and neck squamous cell carcinomas. Acta Otolaryngol 2004; 124(4): 520-526. DOI: https://doi.org/10.1080/00016480310016893

16. Benard VB, Johnson CJ, Thompson TD, et al. Examining the association between socioeconomic status and potential human papillomavirus-associated cancers. Cancer 2008; 113(10 Suppl): 2910-2918. DOI: https://doi.org/ 10.1002/cncr.23742

17. Lindel K, Beer KT, Laissue J, et al. Human papillomavirus positive squamous cell carcinoma of the oropharynx: a radiosensitive subgroup of head and neck carcinoma. Cancer 2001; 92(4): 805-813. DOI: https://doi.org/10.1002/ 1097-0142(20010815)92:4<805::aid-cncr1386>3.0.co;2-9 
18. Butz K, Geisen C, Ullmann A, et al. Cellular responses of HPV-positive cancer cells to genotoxic anti-cancer agents: repression of E6/E7-oncogene expression and induction of apoptosis. Int J Cancer 1996; 68(4): 506-513. DOI: https://doi.org/10.1002/(SICl)1097-0215(19961115)68:4<506::AID-IJC17>3.0.CO;2-2

19. Boscolo-Rizzo P, Del Mistro A, Bussu F, et al. New insights into human papillomavirus-associated head and neck squamous cell carcinoma. Acta Otorhinolaryngol Ital 2013; 33(2): 77-87.

20. Zengel $P$, Assmann $G$, Mollenhauer $M$, et al. Cancer of unknown primary originating from oropharyngeal carcinomas are strongly correlated to HPV positivity. Virchows Arch 2012; 461(3): 283-290. DOI: https://doi.org/10. 1007/s00428-012-1290-3

21. Straetmans JMJAA, Olthof N, Mooren JJ, et al. Human papillomavirus reduces the prognostic value of nodal involvement in tonsillar squamous cell carcinomas. Laryngoscope 2009; 119(10): 1951-1957. DOI: https://doi.org/ 10.1002/lary.20593

22. Geltzeiler M, Bertolet M, Albergotti W, et al. Staging HPV-related oropharyngeal cancer: validation of AJCC-8 in a surgical cohort. Oral Oncol 2018; 84: 82-87. DOI: https://doi.org/10.1016/j.oraloncology.2018.07.013

23. Taberna M, Mena M, Pavón MA, et al. Human papillomavirus-related oropharyngeal cancer. Ann Oncol 2017; 28(10): 2386-2398. DOI: https://doi.org/10.1093/annonc/mdx304

24. Johnson DE, Burtness B, Leemans CR, et al. Head and neck squamous cell carcinoma. Nat Rev Dis Primers 2020; 6(1): 92. DOI: https://doi.org/10.1038/s41572-020-00224-3

25. Ilmarinen T, Munne P, Hagström J, et al. Prevalence of high-risk human papillomavirus infection and cancer gene mutations in nonmalignant tonsils. Oral Oncol 2017; 73: 77-82. DOI: https://doi.org/10.1016/j.oraloncology.2017. 08.010

26. Dodd RH, Waller J, Marlow LAV. Human papillomavirus and head and neck cancer: psychosocial impact in patients and knowledge of the link — a systematic review. Clin Oncol 2016; 28(7): 421-439. DOI: https://doi.org/10.1016/j. clon.2016.02.012

27. Verhees F, Demers I, Schouten LJ, et al. Public awareness of the association between human papillomavirus and oropharyngeal cancer. Eur J Public Health 2021; 3: ckab081. DOI: https://doi.org/10.1093/eurpub/ckab081

28. Lechner M, Vassie C, Kavasogullari C, et al. A cross-sectional survey of awareness of human papillomavirusassociated oropharyngeal cancers among general practitioners in the UK. BMJ Open 2018; 8(7): e023339. DOI: https://doi.org/10.1136/bmjopen-2018-023339

29. Batenburg R, van der Velden L, Vis E, Kenens R. [Numbers from the registration of general practitioners - an update of employment rates of 2018 and 2019] Cijfers uit de registratie van huisartsen - een update van de werkzaamheidscijfers voor 2018 en 2019 (in Dutch). Utrecht: Nivel; 2019.

30. Capaciteitsorgaan. [Capacity plan 2021-2024: Report 2 General Practice] Capaciteitsplan 2021-2024; Deelrapport 2 Huisartsgeneeskunde (in Dutch). 2019; https://capaciteitsorgaan.nl/app/uploads/2019/12/Capaciteitsplan-2021 2024-Deelrapport-2-Huisartsgeneeskunde.pdf (accessed 15 Oct 2021).

31. Jackowska J, Bartochowska A, Karlik M, et al. The knowledge of the role of papillomavirus-related head and neck pathologies among general practitioners, Otolaryngologists and trainees. A survey-based study. PLoS One 2015; 10(10): e0141003. DOI: https://doi.org/10.1371/journal.pone.0141003

32. Hassona $Y$, Scully $C$, Shahin $A$, et al. Factors influencing early detection of oral cancer by primary health-care professionals. J Cancer Educ 2016; 31(2): 285-291. DOI: https://doi.org/10.1007/s13187-015-0823-2

33. Hertrampf K, Wenz HJ, Koller M, et al. Knowledge of diagnostic and risk factors in oral cancer: results from a largescale survey among non-dental healthcare providers in northern Germany. J Craniomaxillofac Surg 2014; 42(7): 1160-1165. DOI: https://doi.org/10.1016/j.jcms.2014.02.001

34. Signorelli C, Odone A, Pezzetti F, et al. [Human papillomavirus infection and vaccination: knowledge and attitudes of Italian general practitioners]. Epidemiol Prev 2014; 38(6 Suppl 2): 88-92.

35. Marlow LAV, Zimet GD, McCaffery KJ, et al. Knowledge of human papillomavirus (HPV) and HPV vaccination: an international comparison. Vaccine 2013; 31(5): 763-769. DOI: https://doi.org/10.1016/j.vaccine.2012.11.083

36. Williams MU, Carr MM, Goldenberg D. Public awareness of human papillomavirus as a causative factor for oropharyngeal cancer. Otolaryngol Head Neck Surg 2015; 152(6): 1029-1034. DOI: https://doi.org/10.1177/ 0194599815577781

37. Lechner M, Jones OS, Breeze CE, Gilson R. Gender-neutral HPV vaccination in the UK, rising male oropharyngeal cancer rates, and lack of HPV awareness. Lancet Infect Dis 2019; 19(2): 131-132. DOI: https://doi.org/10.1016/ S1473-3099(18)30802-8 